\title{
Exploring Study of Yogyakarta Physical Fitness Athletes in Indonesia
}

\author{
Risti Nurfadhila ${ }^{1}$, Tomoliyus ${ }^{1, *}$, Abdul Alim ${ }^{2}$, Japhet Ndayisenga ${ }^{3}$, Endang Rini Sukamti ${ }^{1}$ \\ ${ }^{1}$ Faculty of Sport Sciences, Yogyakarta State University, Indonesia \\ ${ }^{2}$ Institute of Physical Education and Sports, University of Yogyakarta, Indonesia \\ ${ }^{3}$ Institute of Physical Education and Sports, University of Burundi, Indonesia
}

Received October 6, 2021; Revised December 22, 2021; Accepted January 16, 2022

\section{Cite This Paper in the following Citation Styles}

(a): [1] Risti Nurfadhila, Tomoliyus, Abdul Alim, Japhet Ndayisenga, Endang Rini Sukamti, "Exploring Study of Yogyakarta Physical Fitness Athletes in Indonesia," International Journal of Human Movement and Sports Sciences, Vol. 10, No. 1, pp. 38 - 44, 2022. DOI: 10.13189/saj.2022.100106.

(b): Risti Nurfadhila, Tomoliyus, Abdul Alim, Japhet Ndayisenga, Endang Rini Sukamti (2022). Exploring Study of Yogyakarta Physical Fitness Athletes in Indonesia. International Journal of Human Movement and Sports Sciences, 10(1), 38 - 44. DOI: $10.13189 /$ saj.2022.100106.

Copyright $\bigcirc 2022$ by authors, all rights reserved. Authors agree that this article remains permanently open access under the terms of the Creative Commons Attribution License 4.0 International License

\begin{abstract}
Background: Physical fitness training is very important for sports performance. The objective is to assess the different capacities of athletes like speed, strength, flexibility, leg muscle power, and $\mathrm{VO}_{2} \max$. The purpose of this study was: (1) to determine the current status of physical fitness of Yogyakarta athletes, (2) to compare the physical fitness performance on the standard's physical fitness value, (3) to show the effects of physical fitness on the athlete's performance. Research methodology: this is exploring research with a mixed-method qualitative and quantitative study. The sample of this study was 39 subjects from Yogyakarta. The subjects were taken randomly. The subjects were aged between 13-18 years, and they were from many various parties of Yogyakarta. The content of the training was squat jumps: 10 to 15 repetitions, standard push-ups: 10 to 15 repetitions, calf raises 15 to 20 repetitions, bench dips: 10 to 15 repetitions, abdominal crunches: 15 to 20 repetitions, jump rope: 60 seconds, plyometric exercise, sit-ups, press-ups, squats, lunges, and step-ups within three times per week for six weeks. The facts series technique was a physical battery test on the playground. Data were analyzed with descriptive statistics. The result showed that Yogyakarta athletes still have low physical fitness with a P-value of 0.000 . Conclusion: Yogyakarta athletes still hold low physical fitness like speed, $\mathrm{VO}_{2} \mathrm{Max}$, flexibility, explosive strength, power, and coordination.
\end{abstract}

Keywords Strength, Flexibility, Endurance

\section{Introduction}

Muscle capacity evaluation is an essential factor in the performance of an athlete. Coaches should be geared up with the potential to determine the bodily capabilities of athletes earlier than proceeding with training applications [1]. The physical fitness traits are properly defined as (1) Force: the capacity to cross a mass. (2) Flexibility: amplitude of motion that a joint can achieve, (3) Speed: capacity to move in a minimum of time, (4) Resistance: the potential to perform very vital muscular work for a short length of time, (5) Endurance: possibility of performing non-stop effort over a long duration of time, (6) Coordination: the potential to chain actions to gain a specific gesture [2].

The physical fitness test has a tremendous vital for every sports fields administration like: (1) for athletes: recognize their strengths and weaknesses, (2) for training: be aware of the possibilities and limits (trainability): optimize potential, define the content of the education (load), (3) for the coach: measure adaptation, development or regression: establish a work program, validate steps and set priorities or objectives, (4) for the institution: measure, classify and evaluate capacities and aptitudes: identify talents, bring potentials collectively, build teams[3-5]. 
There are many physical fitness ways: walking, cycling, running, sports balls, and recreational activities (for example, dancing, yoga, tai chi). Physical activity can also be practiced at work and home. All forms of physical activity can be beneficial to health when practiced regularly with intensity and for a sufficient period [6-7]

Physical activity is important at any age. Play and active leisure are important for early childhood and the growth and healthy development of children and teenagers [8]. Quality bodily schooling and supportive school environments can supply statistics on physical activity and health from a long-term healthy and active life. It is also vital that adults are bodily lively and much less passive. Whether they work or not, older people, in particular, can interact in normal bodily undertakings to maintain physical, mental, and social health. Still, a bodily check-in is needed to easily orient the education [9].

Sprint training exercise skills are very important in each sport to increase performance [10]. Research results show a direct correlation between the reaction time and the performance. The degrees of correlation varies depending on the athlete's gender, year of competition, type of competition, and the round of competition [11]. Not surprisingly, exercise training across a wide range of intensities is an effective ( $\mathrm{T}=0.73 ; 95 \%$ CI $1.35,0.11)$ means of increasing $\mathrm{VO}_{2}$ max in young, healthy adults (39 of 40 study groups reported a positive effect of training [12].

One study showed that the countermovement jump test determined how muscles were apt to allow performance through concentric and eccentric movements within respective $P$ values: $(\mathrm{P} \leq 0.033) ;(\mathrm{P}=0.002)$ [13]. The energy and pace variables have been dependable from the factor the place force became into an increasing price while displacement from minimal speed was once reached. Net impulse and ratios of pressure development confirmed high and suited values [14]. The Counter Movement Jump (CMJ) is widely used as a discipline test to evaluate the muscular explosive power of decreased limbs in various sports, such as soccer, basketball, volleyball. etc. [15]. The physical fitness test is a great instrument used to assess the abdominal muscular endurance of service members [16]. Physical fitness battery test is more important to reach the athlete's performance [17]. Another research showed that The McGill protocol was positively correlated with the medicine ball throw test $(r=0.688)$ and the vertical jump test $(r=0.463)$. A strong negative correlation of McGill was identified with the 40-yard dash test $(r=-0.525)$ and $\mathrm{T}$-test $(\mathrm{r}=-0.687)$. At the same time, DLL was positively correlated with the 40 -yard dash test $(\mathrm{r}=0.374)$ and T-test $(\mathrm{r}=0.524)$. Only medicine ball throw test-related significantly with the tests of core power [18]. However, one study showed that athletes performed commonly used flexibility tests (stand-and-reach, straddle stand) and climbing-specific flexibility tests. Significant correlations were found between sport skill levels for the straddle stand test $(r=-0.48)$, and the straddle sit test $(r=-0.41)$ [19].

Why is this research important? This study is very important because it will help coach trainers know the strength and wackiness of their athletes while there is a lack of scientific research conducted on athletes' physical fitness. However, good physical finesses like strength, speed, coordination, agility, $\mathrm{VO}_{2} \mathrm{Max}$, accuracy, flexibility, and power were known as the most performance indicators.

Based on the research done and the importance of the physical fitness battery test, it was found that there is no physical fitness test in Yogyakarta country. A strong lack of scientific research characterized Yogyakarta. The basic physical fitness level of Yogyakarta athletes is still unknown. However, if there are no more studies linked to the physical fitness test of athletes, there is no hope to reach the goals or high achievement. This study will help researchers to know the current status of Yogyakarta athletes. The result from the later lookout will also enable physical education and coach trainers to know their athletes' strong and weak points.

\section{Research Methodology}

This is explorative research with a mixed-method qualitative and quantitative study. The research sampling for this study was 29 athletes from Yogyakarta Special Region. The subjects were taken randomly. The subjects were aged between 13-18 years, and they were from various sports fields. The data collection technique was a physical battery test on the playground. Before the physical fitness evaluation, the athletes have been trained within squat jumps: 10 to 15 repetitions, standard push-ups: 10 to 15 repetitions, calf raises: 15 to 20 repetitions, bench dips: 10 to 15 repetitions, abdominal crunches: 15 to 20 repetitions, jump rope: 60 seconds, plyometric exercise, sit-ups, press-ups, squats, lunges, and step-ups within three times per week for six weeks. Data were analyzed with descriptive statistics.

\section{The procedure of Physical Fitness Evaluation}

A battery test was applied to evaluate like (1) Sprint test $30 \mathrm{~m}$, to determine the contraction muscles speed, (2) Schocken test, (3) the flexibility was determined using flexor meter, (4) right triple jump and left triple jump arm, (5) $\mathrm{VO}_{2} \mathrm{Max}$ test to assess the muscle endurance. All the subjects have the battery test at the same time.

\section{Result}

The data have been presented in the form of tables after each mean of the data was compared on normal value to assess if the subjects have good physical fitness. 
Table 1. Physical fitness test battery

\begin{tabular}{|c|c|c|c|c|c|}
\hline $\begin{array}{l}\text { Sprint } 30 \mathrm{~m} \\
\text { (Sec) }\end{array}$ & $\begin{array}{c}\text { Shocken Test } \\
\text { (Meter) }\end{array}$ & $\begin{array}{l}\text { Flexibility } \\
(\mathbf{C m})\end{array}$ & $\begin{array}{c}\text { Right Triple Hope Jump } \\
\text { (Meter) }\end{array}$ & $\begin{array}{c}\text { Left Triple Hope Jump } \\
\text { (Meter) }\end{array}$ & Beep Test \\
\hline 4.75 & 4.8 & 43.2 & 6.12 & 5.5 & 60.8 \\
\hline 4.59 & 5.0 & 42 & 5.7 & 5.85 & 60.6 \\
\hline 4.86 & 6.1 & 43 & 6.05 & 5.93 & 38.2 \\
\hline 4.84 & 4.8 & 38 & 5.15 & 4.8 & 27.5 \\
\hline 6.75 & 3.7 & 43 & 4.68 & 4.5 & 20 \\
\hline 5.45 & 7.3 & 21 & 4.4 & 4.41 & 26.8 \\
\hline 4.27 & 9.0 & 50 & 7.4 & 7.5 & 57.4 \\
\hline 4.16 & 8.6 & 42.5 & 7.5 & 7.16 & 62.2 \\
\hline 4.26 & 8.0 & 51.5 & 6.5 & 5.75 & 50.8 \\
\hline 5.41 & 6.0 & 29 & 4.7 & 4.2 & 26.4 \\
\hline 6.84 & 3.4 & 27 & 3.77 & 3.94 & 21.6 \\
\hline 4.36 & 8.7 & 41 & 5.53 & 6.6 & 57.9 \\
\hline 4.73 & 5.7 & 48.7 & 6.35 & 5.74 & 55.4 \\
\hline 4.45 & 7.5 & 43.5 & 5.41 & 5.8 & 54.3 \\
\hline 5.70 & 6.4 & 30 & 4.24 & 4.26 & 33.2 \\
\hline 4.71 & 6.0 & 41 & 5.65 & 6.11 & 49.6 \\
\hline 4.61 & 5.3 & 43.5 & 6.26 & 6.68 & 50.5 \\
\hline 4.77 & 8.7 & 46.5 & 6.7 & 6.88 & 51.4 \\
\hline 4.71 & 8.1 & 45.5 & 5.53 & 6.12 & 41.1 \\
\hline 4.51 & 6.0 & 43 & 5.43 & 6.01 & 53.1 \\
\hline 4.48 & 5.7 & 50 & 5.58 & 5.26 & 47.4 \\
\hline 4.54 & 5.9 & 41 & 5.59 & 6.37 & 56.3 \\
\hline 4.43 & 6.7 & 47 & 6.72 & 6.27 & 54.8 \\
\hline 4.09 & 7.5 & 47 & 6.93 & 6.48 & 56.5 \\
\hline 4.14 & 8.2 & 46 & 7.41 & 7.8 & 51.9 \\
\hline 4.05 & 7.9 & 51 & 5.71 & 5.64 & 51.9 \\
\hline 4.23 & 7.5 & 34.5 & 6.51 & 6.45 & 47.1 \\
\hline 4.25 & 8.1 & 46 & 6.52 & 6.49 & 50.8 \\
\hline 4.14 & 6.8 & 47 & 6.45 & 6.5 & 54.3 \\
\hline 4.75 & 7.7 & 48 & 6.99 & 5.6 & 59.8 \\
\hline 4.15 & 7.5 & 43 & 6.72 & 6.53 & 54.3 \\
\hline 4.49 & 5.5 & 46 & 5.46 & 5.1 & 51.1 \\
\hline 4.44 & 6.0 & 42 & 6.65 & 6.66 & 50.5 \\
\hline 4.61 & 7.2 & 48 & 7.41 & 7.25 & 53.7 \\
\hline 4.66 & 8.0 & 46 & 6.24 & 6.03 & 49.3 \\
\hline 6.30 & 4.9 & 40 & 4.47 & 4.13 & 30.2 \\
\hline 5.54 & 4.2 & 38 & 4.01 & 4.16 & 26.4 \\
\hline 6.22 & 6.8 & 42 & 4.25 & 4.3 & 27.6 \\
\hline 5.58 & 4.8 & 46 & 4.84 & 4.2 & 26.8 \\
\hline Mean 4.82 & Mean 6.57 & Mean 42.07 & Mean 5.83 & Mean 5.77 & Mean 46.14 \\
\hline SD 0.73 & SD 1.48 & SD 7.09 & SD 1.02 & SD 1.05 & SD 12.62 \\
\hline
\end{tabular}


The result found out in table 1 showed that the sprint mean test was $4.82 \mathrm{sec}$ for $30 \mathrm{~m}$. Comparing the found result to the reference value like $3.58 \mathrm{sec}$ for $30 \mathrm{~m}$, the researchers concluded that people must have speed training exercises to expect high performance. The later speed (4.82 sec for $30 \mathrm{~m}$ ) stills in low level comparing to the standard value. The following time showed that the subject had a bad time. The more the time is taller, the more the performance is worse. The result predicts that the athletes still need speed training exercise. The standard deviation of 0.73 showed that people were not different about the speed.

The result showed that athletes have a low level of power and coordination using the Shocken test. The result showed a strongly significant difference (P value; .000) between the found development and the standard of Shocken test, like $11,76 \mathrm{~m}$ was taken as a good reference. Therefore, athletes still need a power training exercise and coordination exercise to achieve high performance

Based on the result found above, the flexibility was assessed according to the standard value as presented in table 2.

Table 2. The usual values of flexibility

\begin{tabular}{|c|c|c|}
\hline Fitness category & Males & Females \\
\hline Good & $46.5-38.0$ & $45.5-38.0$ \\
\hline Average & $37.5-27.0$ & $37.5-29.0$ \\
\hline Below Average & $26.5-17.0$ & $28.5-20.0$ \\
\hline Not very flash! & $<17.0$ & $<20.0$ \\
\hline
\end{tabular}

Table 1 showed that the mean of the flexibility result was 42.07. Regarding the common value from table 2, most people have good flexibility. Concretely, stretching makes the muscles more elastic and maintains the body's mobility. A moving body is a healthier body, and this helps to prevent injury. The more the athletes have high flexibility, the more they will perform motion exercises. Flexibility is much needed in every sports field to allow good performance and prevent injuries.

The result from table 1 showed that triple hop jump test mean was about 5.83 in the right leg, and 5.77 in the left leg. The following standard showed no significant difference between right and left. The status of this sample showed a significant difference with P-value;.000 between the found data and the value of the standard respectively from the right and left: $8.18 \mathrm{~m} ; 8.05 \mathrm{~m}$ were taken as references value to determine the good power of quadriceps muscles. The above result showed that the athletes still need explosive training exercises to improve explosivity leg muscles as it is known that the three-hop test is a test of explosive leg power. In which the athlete has to perform three consecutive horizontal jumps. They were taking off one leg at once for each jump. This test aims to achieve three consecutive single-leg hops as far as possible. Record the longest distance jumped from three trials.

The result from table 1 showed that $\mathrm{VO}_{2}$ max means was 46.14. This one has been compared on the standard according to the subjects aged. The statistical analysis with ANOVA one way showed a strongly significant difference between the subject $\mathrm{VO}_{2} \max$ and the expected value. According to the age of the participants. And based on the American Association of Health, research done showed that a $\mathrm{VO}_{2}$ max within 53 was found good for people under 29 ages.

Regarding the sample research, it was found that the subjects still have a low $\mathrm{VO}_{2} \max . \mathrm{VO}_{2} \max$ a performance indicator. The higher value it is, the more the athlete can maintain an effort of a certain intensity over time. Suppose the athlete increases his $\mathrm{VO}_{2}$ max through training, he can run either faster for the same distance or longer for the same power.

Table 3. One-Sample Test of $\mathrm{VO}_{2} \max$

\begin{tabular}{|c|c|c|c|c|c|c|}
\hline & & & & Test Value $=53$ & \\
\cline { 5 - 7 } & \multirow{2}{*}{$\mathrm{t}$} & $\mathrm{df}$ & Sig. (2-tailed) & Mean Difference & \multicolumn{2}{|c|}{ 95\% Confidence Interval of the Difference } \\
\cline { 5 - 7 } & & & & Lower & Upper \\
\hline $\mathrm{VO}_{2} \max$ & -3.395 & 38 & .002 & -6.85897 & -10.9488 & -2.7691 \\
\hline
\end{tabular}


The result from table 3 showed a significant difference between $\mathrm{VO}_{2} \max$, and the standard value (53). Its value varies from 25 to $70 \mathrm{ml} / \mathrm{min} / \mathrm{kg}$ in women and from 30 to $90 \mathrm{ml} / \mathrm{min} / \mathrm{kg}$ in men. Purely as an indication, it is the order of $30 \mathrm{ml} / \mathrm{min} / \mathrm{kg}$ in sedentary humans, $50-60 \mathrm{ml} / \mathrm{min}$ $/ \mathrm{kg}$ in trained sportsmen, and reaches 80 to more than 90 $\mathrm{ml} / \mathrm{min} / \mathrm{kg}$ in the top athlete. The following sample still needs cardio-vascular exercise, and aerobic exercise.

\section{Discussion}

The result showed that most subjects have a low level compared to the normal value. The Sprint or velocity exams can be performed over varying distances. They depended on the elements being examined and the relevance to the athlete's sport. Purpose: The cause of this test is to decide acceleration. Most are going for walks velocity and velocity endurance, depending on the distance run. The result found showed that there is a great difference between their mean and the reference means with P-value .000. It is important to always evaluate the physical fitness of athlete in order to know the weakness and the strengthening of the athlete [20]. The result showed that the mean of flexibility was good, which allows the subject to perform their motion during the exercise or the game. Many research showed that flexibility is the ability to move muscles and joints through a full normal range of motion (ROM). Flexibility helps performance, posture, promotes efficient movement, prevents incorrect body alignment, maintains appropriate muscle length and balance and also decreases injury risk. However, the flexibility improved the overall performance of day-by-day activities, and improved overall performance in workout and sport

They have enhanced joint health, prevention of low-back pain and injuries, relief of aches and pains (particularly in the muscular tissues exercised), relief of muscle cramps, relaxation and stress comfort (mental and physical), decreased threat of harm due to more pliable muscles and improved posture and stability [21]. The $\mathrm{VO}_{2} \mathrm{max}$ from the above result is still in low condition compared to the standard value. Some research showed that $\mathrm{VO}_{2} \mathrm{max}$ and VT2 increase with a higher volume of kilometers trained and can be adversely affected by the loss of muscle mass. Although their associated running speeds increased $(\mathrm{p}<$ 0.05 ) after three months of the study [22]. The relation between $\mathrm{VO}_{2} \max$ and training volume intensity was performed using multi-regress. The result showed a strong correlation between them with $\mathrm{r}:-0.91$ to -0.96 . The following result showed that the training intensity increases $\mathrm{VO}_{2} \mathrm{Max}$ [23-24]. Endurance muscle is very important for each type of sport. However, the triple hop jump test result was not suitable in the right and left. This one showed that plyometric exercise is still needed to improve muscle explosivity. The research showed that plyometric training had a significant effect on $\mathrm{CMJ}$ performance. Participants aged $\geq 16$ years achieved greater improvements in $\mathrm{CMJ}$ performance compared to $<16$ years old ( $\mathrm{ES}=1.28$ and 0.38. respectively; $p=0.022$ ) [25]. Plyometric training (PT) on vertical jump in young basketball athletes benefits from increasing muscle power and endurance [26]. Thus, the existing evaluation shows an increased impact of PT on my own on soar and sprint $(30 \mathrm{~m}$ dash performance only) than the aggregate of PT with sprint/strength training. However, many issues associated with PT remain to be resolved. The effects presented in this evaluation allow recommending well-designed and sport-specific PT as a protected and good coaching modality for improving jumping and dash performance as properly as agility in team sport athletes [27].

In Yogyakarta, trainers need to improve their training programs again to allow the athlete to reach high performance in different sports fields. Physical fitness is more based on age, nutrition, gender, climate, environment program training, the qualification of the coach [28]. The causes of the low physical fitness of Yogyakarta athletes are, among others, the lack of training, the unsuitable training programs, the insufficient knowledge of some coach's trainers. Speed tests, flexibility exercises, aerobic and plyometric exercises are more beneficial for the athlete to improve muscles speed, core strength, posture, balance, athlete performance, academic achievement, and reduce the risk of human body injuries [29]. The global result from this study showed that Yogyakarta athletes have low physical fitness except for the flexibility in good condition. They still need more suitable programs to allow them to reach high performance.

\section{Conclusions}

This study was about to investigate the current status of Yogyakarta athletes on chosen variables like speed, flexibility, power, $\mathrm{VO}_{2} \mathrm{Max}$, explosivity strengthen. The problem was to assess if Yogyakarta athletes have a qualified level for each parameter. The result showed a low physical level compared to the normal value except for flexibility. The result constitutes a good way or statement to help coaches' trainers from Yogyakarta to remember to assess various physical fitness athletes. The research is also recommended for the following study. An interested researcher could consider the CMJ coordination, agility, grip strength, muscle, and accuracy.

\section{REFERENCES}

[1] S. D. E. C. Fauteuil, C. Fédéral, and G. Patrice, "Departement des sciences du sport 1," pp. 1-54, 2004.

[2] D. M. Inocentio, "Condition physique et santé : du 
diagnostic à 1, activité physique personnalisée chez le senior ( ASM Vitaly Test ) To cite this version : HAL Id : tel-02513904 Condition physique et santé : du diagnostic à 1 ' activité physique personnalisée chez le sen," 2020.

[3] G. Markovic, D. Dizdar, I. Jukic, and M. Cardinale, "Reliability and factorial validity of squat and countermovement jump tests," J. Strength Cond. Res., vol. 18, no. 3, pp. 551-555, 2004, doi: 10.1519/15334287(2004 )18<551:RAFVOS $>2.0 . \mathrm{CO} ; 2$.

[4] R. M. Acero, J. A. Sánchez, and M. Fernández-del-Olmo, "Tests of Vertical Jump," Strength Cond. J., vol. 34, no. 6, pp. 87-93, 2012, doi: 10.1519/ssc.0b013e318276c353.

[5] T. Ambroży et al., "The impact of reduced training activity of elite kickboxers on physical fitness, body build, and performance during competitions," Int. J. Environ. Res. Public Health, vol. 18, no. 8, 2021, doi: 10.3390/ijerph180 84342 .

[6] OMS, Plan d'action mondial de l'oms pour promouvoir l'activité physique 2018-2030. 2018.

[7] P. Polero et al., "Physical activity recommendations during COVID-19: Narrative review," Int. J. Environ. Res. Public Health, vol. 18, no. 1, pp. 1-24, 2021, doi: 10.3390/ijerph18010065.

[8] J. Ndayisenga and Tomoliyus, "The perception of international students on the facility and sport tourism event management," Sport Mont, vol. 17, no. 2, pp. 53-58, 2019, doi: $10.26773 /$ smj.190609.

[9] M. Turgut, Y. Soylu, and S. N. Metin, "Physical activity, night eating, and mood state profiles of athletes during the COVID-19 pandemic," Prog. Nutr., vol. 22, no. 6, 2020, doi: 10.23751/pn.v22i2-S.10567.

[10] R. G. Lockie, A. J. Murphy, A. B. Schultz, T. J. Knight, and X. A. K. J. De Jonge, "The effects of different speed training protocols on sprint acceleration kinematics and muscle strength and power in field sport athletes," $J$. Strength Cond. Res., vol. 26, no. 6, pp. 1539-1550, 2012, doi: 10.1519/JSC.0b013e318234e8a0.

[11] J. Zhang, X. Y. Lin, and S. Zhang, "Correlation Analysis of Sprint Performance and Reaction Time Based on Double Logarithm Model," Complexity, vol. 2021, 2021, doi: $10.1155 / 2021 / 6633326$.

[12] T. D. Scribbans, S. Vecsey, P. B. Hankinson, W. S. Foster, and B. J. Gurd, "The Effect of Training Intensity on $\mathrm{VO}_{2}$ max in Young Healthy Adults: A Meta-Regression and Meta-Analysis.," Int. J. Exerc. Sci., vol. 9, no. 2, pp. 230 247, [Online]. Available: http://www.ncbi.nlm.nih.gov/pub med/27182424\%0Ahttp://www.pubmedcentral.nih.gov/arti clerender.fcgi?artid=P MC4836566.

[13] Mitchell, C. Holding, and M. Greig, "Factors influencing optimum countermovement jump performance and movement strategy in Championship professional football players: implications for player profiling," Res. Sport. Med., vol. 00 , no. $00, \quad$ pp. 1-11, 2020, doi: $10.1080 / 15438627.2020 .1860049$

[14] D. M. Warr, C. Pablos, J. V. Sánchez-Alarcos, V. Torres, J. M. Izquierdo, and J. Carlos Redondo, "Reliability of measurements during countermovement jump assessments: Analysis of performance across subphases," Cogent Soc.
Sci., vol. 6, no. 1, 2020, doi: 10.1080/23311886.2020.1843 835 .

[15] L. Quagliarella, N. Sasanelli, G. Belgiovine, D. Accettura, A. Notarnicola, and B. Moretti, "Evaluation of counter movement jump parameters in young male soccer players," J. Appl. Biomater. Biomech., vol. 9, no. 1, pp. 40-46, 2011, doi: 10.5301/JABB.2011.7732.

[16] Bianco et al., "The sit up test to exhaustion as a test for muscular endurance evaluation," Springerplus, vol. 4, no. July, 2015, doi: 10.1186/s40064-015-1023-6.

[17] L. Petrigna et al., "Physical fitness assessment in Goalball: A scoping review of the literature," Heliyon, vol. 6, no. 7, p. e04407, 2020, doi: 10.1016/j.heliyon.2020.e04407.

[18] I. Shaikh, S. Nuhmani, S. J. Kachanathu, and Q. I. Muaidi, "Relationship of core power and endurance with performance in random intermittent dynamic type sports," Asian J. Sports Med., vol. 10, no. 1, pp. 1-7, 2019, doi: 10.5812/asjsm.62843.

[19] P. Draga et al., "Importance and diagnosis of flexibility preparation of male sport climbers," Int. J. Environ. Res. Public Health, vol. 17, no. 7, pp. 6-8, 2020, doi: 10.3390/ijerph17072512.

[20] L. DiPietro, D. M. Buchner, D. X. Marquez, R. R. Pate, L. S. Pescatello, and M. C. Whitt-Glover, "New scientific basis for the 2018 U.S. Physical Activity Guidelines," J. Sport Heal. Sci., vol. 8, no. 3, pp. 197-200, 2019, doi: 10.1016/j.jshs.2019.03.007.

[21] Konrad, R. Močnik, M. Nakamura, K. Sudi, and M. Tilp, "The Impact of a Single Stretching Session on Running Performance and Running Economy: A Scoping Review," Front. Physiol., vol. 11, no. January, pp. 1-12, 2021, doi: 10.3389/fphys.2020.630282.

[22] Granero-Gallegos, A. González-Quílez, D. Plews, and M. Carrasco-Poyatos, "Hrv-based training for improving $\mathrm{vo}_{2} \mathrm{max}$ in endurance athletes. A systematic review with meta-analysis," Int. J. Environ. Res. Public Health, vol. 17, no. 21, pp. 1-22, 2020, doi: 10.3390/ijerph17217999.

[23] Foster, " $\mathrm{Vo}_{2} \mathrm{max}$ and training indices as determinants of competitive running performance," J. Sports Sci., vol. 1, no. 1, pp. 13-22, 1983, doi: 10.1080/02640418308729657.

[24] V. Issurin, V. Pushkar-Verbitsky, and O. Verbitsky, "Effect of high-tech swimsuits on the swimming performance in top-level swimmers," J. Sports Med. Phys. Fitness, vol. 54, no. 4, pp. 383-388, 2014.

[25] R. Ramirez-Campillo et al., "Effects of plyometric jump training on vertical jump height of volleyball players: A systematic review with meta-analysis of randomized-controlled trial," J. Sport. Sci. Med., vol. 19, no. 3, pp. 489-499, 2020.

[26] G. A. Fernandes Correia et al., "The effect of plyometric training on vertical jump performance in young basketball athletes," J. Phys. Educ., vol. 31, no. 1, pp. 1-8, 2021, doi: 10.4025/JPHYSEDUC.V31I1.3175.

[27] M. Slimani, K. Chamari, B. Miarka, F. B. Del Vecchio, and F. Chéour, "Effects of Plyometric Training on Physical Fitness in Team Sport Athletes: A Systematic Review," $J$. Hum. Kinet., vol. 53, no. 1, pp. 231-247, 2016, doi: 10.1515/hukin-2016-0026. 
[28] Peterson, M. Middleton, and S. Christman, "Evaluation of Possible Anthropometric Advantage in Sit-Up Test," Sport J., vol. 20, pp. 1-10, 2019.
[29] J. D. Childs et al., "Effects of sit-up training versus core stabilization exercises on sit-up performance," Med. Sci. Sports Exerc., vol. 41, no. 11, pp. 2072-2083, 2009, doi: 10.1249/MSS.0b013e3181a84db2. 